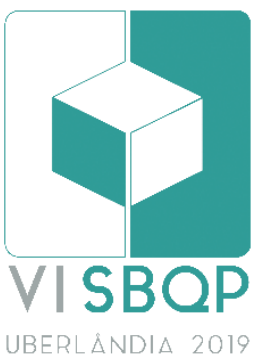

\title{
COPRODUÇÃO E RESILIÊNCIA EM HABITAÇÃO SOCIAL: O CASO DO BAIRRO SHOPPING PARK
}

\author{
VILLA, Simone Barbosa \\ FAUeD/UFU, e-mail: simonevilla@yahoo.com.br \\ REZENDE DE DEUS, Rafaela \\ FAUeD/UFU, e-mail: rafaelarez@hotmail.com \\ SOUZA, Aline Ribeiro \\ FAUeD/UFU, e-mail: alineribeiro@ufu.br
}

\begin{abstract}
RESUMO
O rápido e descontrolado crescimento populacional urbano propiciou novos desafios as cidades brasileiras, e como fornecer moradia para a população de baixa renda foi um deles. $\mathrm{Na}$ tentativa de reduzir o déficit habitacional, o governo acaba entregando moradias com baixa qualidade e pouco resilientes, por conseguinte os moradores modificam suas casas dentro dos recursos disponíveis na intenção de superar tais adversidades. O artigo apresenta parte da pesquisa em curso "[RES_APO 2 e 3] Resiliência e Adaptabilidade em Conjuntos Habitacionais Sociais através da Coprodução". A pesquisa-ação tem como foco a capacidade de adaptação, transformação e resiliência do ambiente construído no atendimento às necessidades de seus moradores. Para verificação, as técnicas desenvolvidas foram aplicadas em estudo de caso na cidade de Uberlândia. O objetivo desse artigo é apresentar os principais resultados das coproduções realizadas até o momento. Essa experiência pode promover uma diferença real e prática aos residentes no Brasil e proteger o futuro, fornecendo orientações detalhadas para o projeto de habitação mais adaptável e resiliente em um contexto local, comprovado através de um estudo de Coprodução. Desta forma a pesquisa também está alinhada às Agendas nacionais e internacionais de desenvolvimento sustentável.
\end{abstract}

Palavras-chave: Habitação de Interesse Social, Coprodução, Resiliência, Adaptabilidade, Comunidade.

\begin{abstract}
The quick and uncontrolled urban population growth provide new challenges to the Brazilian cities, and how to afford houses for low-income people was one of them. In the attempt to reduce the housing deficit, the government ends up delivering low quality houses and low resilience, consequently the residents make changes on theirs houses within the resources available in the intention of overcome such adversities. The paper presents part of the research in-progress named "[RES_APO 2 e 3] Resilience and Adaptability in Social Housing Complexes through Co-production". The research-action have as focus the capacities of adaptation, transformation and resilience of the built environment in the service to their resident's needs. For verification, the developed techniques were applied in case study in the city of Uberlândia. The aim of this paper is to present the principal results of the co-production realized until the moment. This experience can promote a real and practical difference to the residents in Brazil and protect the future, providing detailed guidelines to the project of habitation more adaptable and resilient on a local context, established thought the study of co-production. Thus, the research is also aligned to the national and international agendas of sustainable development.
\end{abstract}

Keywords: Social Housing Complexes, Co-production, Resilience, Adaptability, Community.

VILLA, S.; REZENDE DE DEUS, R.; SOUZA, A. R. Coprodução e resiliência em habitação social: o caso do bairro Shopping Park. In: SIMPÓSIO BRASILEIRO DE QUALIDADE DO PROJETO NO AMBIENTE CONSTRUÍDO, 6., 2019, Uberlândia. Anais... Uberlândia: PPGAU/FAUeD/UFU, 2019. p. 411-427. DOI https://doi.org/10.14393/sbqp19039. 


\section{INTRODUÇÃO}

Historicamente o Brasil possui problemas com a insuficiência de moradias para a população de baixa renda, derivado do alto crescimento populacional e urbano. Portanto com o intuito de reduzir o déficit habitacional, o governo brasileiro lançou em 2009 o programa Minha Casa Minha Vida (MCMV), proveniente de uma parceria entre o governo e o setor privado, e desde então responsável pela produção de 4,4 milhões de unidades habitacionais. Contudo, de acordo a Fundação João Pinheiro (BOHM, 2018) mesmo após 10 anos do programa os mais recentes dados (2015) apontam um déficit habitacional de aproximadamente 6,3 milhões e de aproximadamente 11,3 milhões de famílias vivendo em moradias de baixa qualidade. Conforme comprovado por vários estudos de pós-ocupação, as problemáticas estão presentes desde a escala da casa com a baixa qualidade da arquitetura (AMORE, SHIMBO e RUFINO, 2015; GRANJA et al., 2009) até a escala urbana, no qual geram áreas monofuncionais e homogêneas - carecendo de infraestrutura, serviços e equipamentos adequados.

As problemáticas afetam principalmente as famílias de baixa renda, que em busca da casa própria, acabam vivendo em condições precárias e tendo que lidar à sua maneira com as adversidades. Portanto, os moradores realizam interferências por conta própria, sem algum acompanhamento profissional, de acordo com seus recursos, na tentativa de superar os problemas presentes nas suas moradias.

Em detrimento das mudanças sociais e climáticas e da baixa qualidade da arquitetura e urbanismo, que geram casas inadequadas, o objetivo da pesquisa é implementar e potencializar a resiliência e a adaptabilidade em Conjuntos Habitacionais de Interesse Social (CHIS) através de técnicas de coprodução e empoderar o engajamento da comunidade, contribuindo para a emancipação dos moradores socialmente e politicamente. Portanto o presente artigo apresenta parte da pesquisa em desenvolvimento "[RES_APO 2 e 3] Resiliência e Adaptabilidade em Conjuntos Habitacionais Sociais através da Coprodução", com foco nas atividades colaborativas e na coprodução em andamento, subsidiando as reflexões sobre como construir com resiliência.

\section{FUNDAMENTAÇÃO TEÓRICA}

\subsection{Resiliência e Adaptabilidade}

O conceito tradicional de resiliência está associado à capacidade de um sistema para absorver distúrbios e reorganizar-se quando sujeita a alterações, e ao mesmo tempo ser capaz de manter as suas funções essenciais, estrutura, identidade e mecanismos (WALKER et al., 2004; THACKARA, 2008). O termo tradicionalmente aplicado a área da física e da ecologia, tem sido aplicado em campos como as relações humanas e as dinâmicas urbanas, onde pode ser entendida como um estado contrário à vulnerabilidade (IPCC, 2014).

Resiliência tornou-se um conceito popular e um importante objetivo no planejamento das cidades, principalmente se tratando de desastres ambientais e mudanças climáticas (MEEROW, NEWELL, STULTS, 2015). Com base em agendas urbanas relevantes, como a Nova Agenda Urbana - Habitat 
III' (New Urban Agenda, 2017) e Sustainable Development Goals - AGENDA $2030^{2}$ (Sustainable Development Goals, 2015), a resiliência é definida como uma força motriz no combate ao estado vulnerável proporcionado pelo rápido crescimento da população urbana e outros problemas causados pela urbanização inadequada.

$\mathrm{Na}$ pesquisa adotou-se a definição estabelecida por Maguire e Cartwright (2008), que é mais positiva e evolutiva em relação à resiliência social. Essa abordagem identifica os recursos e a capacidade de adaptação que uma comunidade pode utilizar para superar os problemas que podem resultar da mudança. Baseia-se nas capacidades inerentes de uma comunidade, ao invés de apenas confiar em intervenções externas para superar vulnerabilidades. A resiliência social tem dimensões econômicas, políticas, espaciais, institucionais e sociais (ADGER, 2000). Uma comunidade resiliente é capaz de responder às mudanças ou estresse de uma forma positiva, e é capaz de manter suas funções essenciais como uma comunidade, apesar dessas tensões. Uma mudança específica pode ter consequências muito diversas em diferentes comunidades, e diferentes comunidades demonstrarão diferentes graus de resiliência à mudança (KELLY, 2004).

\subsection{Avaliação Pós-Ocupação}

A Avaliação Pós Ocupação (APO) é uma ferramenta de pesquisa já extremamente alicerçada na área da construção civil tanto nacionalmente (ELALI e VELOSO, 2006; ORNSTEIN, VILLA e ONO, 2010; VILLA e ORNSTEIN, 2013; VOORDT e WEGEN, 2013, ONO et al. 2018) como internacionalmente (LEAMAN; STEVENSON; BORDASS, 2010; PREISER e VISCHER 2005; MALLORY-HILL, PREISER, e WATSON 2012), sendo uma das principais ferramentas usadas de base para essa pesquisa.

A partir da APO, é possível montar um banco de dados com informações que respaldam a verificação da qualidade habitacional no bairro, a análise do comportamento dos usuários no ambiente doméstico, a inspeção sobre a funcionalidade dos ambientes, a avaliação sobre o nível de satisfação dos moradores e, afinal, a observação dos impactos, vulnerabilidades e capacidades adaptativas, incidentes sobre determinado sistema.

\subsection{Coprodução}

A Coprodução tem como pressuposto básico a neutralidade do pesquisador, que trabalha como um facilitador no processo de produção e gerenciamento do espaço. A prática surgiu como reação a um contexto social, político e econômico em que a administração pública não responde em tempo e à altura às demandas urbanas, que se complexificam constantemente.

De acordo com Petcou e Petrescu (2015), não se trata somente de uma forma alternativa de lidar com as demandas públicas, mas também da efetivação do direito à cidade. Entende-se como direito à cidade o acesso à terra urbana e, além disso, o direito à participação nas decisões sobre seu desenvolvimento, uso e gerenciamento. Nesse sentido, a parceria entre academia e sociedade civil, através da adoção de metodologias

\footnotetext{
1 http://habitat3.org.

2 https://sustainabledevelopment.un.org/sdgs.
} 
coprodutivas de trabalho, tem potencial de alcançar benefícios públicos significativos.

Para Campbell e Vanderhoven (2016), nesse tipo de coprodução não há hierarquia de formas de conhecimento, não há limites de atuação e, acima de tudo, impera a preocupação com a ação efetiva. Superam-se modelos tradicionais de abordagem, em que a comunidade não-acadêmica fica restrita a posição de sujeito da pesquisa, e frequentemente não tem acesso às conclusões da pesquisa.

Portanto, enxerga-se a coprodução como uma abordagem relativamente nova para enfrentar os desafios sociais, ambientais e econômicos, a qual tem a capacidade de questionar e mudar as relações de poder dentro do ambiente construído contemporâneo, sua produção, governança e manutenção, para permitir comunidades mais sustentáveis e resistentes (STEVENSON; PETRESCU, 2016).

\section{METODOLOGIA}

O trabalho é composto por três etapas, tendo como objeto principal de estudo o Residencial Sucesso Brasil, localizado no CHIS do bairro Shopping Park, na cidade de Uberlândia (MG):

(i) Ełapa 1 - AVALIANDO. Levantamento da área, com pesquisa de APO, análise de desempenho e coprodução, esta focada no contexto urbano, que identificaram os principais impactos, vulnerabilidades e capacidades adaptativas. Desenvolvida em parceria com o grupo de pesquisa People, Environment and Performance ${ }^{3}$ (SsoA - TUoS/UK) e financiado pelo Banco Santander ${ }^{4}$ (2016);

(ii) Ełapa 2 - AGINDO. Atualização do levantamento da área, pesquisa de APO, análise de desempenho e Início da coprodução enfocando a unidade habitacional (2017 - 2018);

(iii) Ełapa 3 - EMPODERANDO. Consolidação da coprodução enfocando a unidade habitacional. População assume a frente das ações (2018 2019).

O presente projeto de pesquisa, trata das etapas 2 e 3 que versa sobre as ações de coprodução na área de estudo, para implementação da capacidade adaptativa e resiliência do ambiente construído no atendimento às necessidades de seus moradores e o impacto ambiental decorrente dessas transformações.

Apesar da coprodução ser a metodologia principal dessa pesquisa, é importante ressaltar que na etapa 1 (AVALIANDO) ${ }^{5}$ assim como na etapa 2 (AGINDO), foram aplicados diversos instrumentos de APO (Quadro 1), os quais deram respaldo para o desenvolvimento das coproduções e da atividade colaborativa realizadas até o momento.

\footnotetext{
3 https://www.sheffield.ac.uk/architecture/people/academic/fionn-stevenson.

4 Santander Research Mobility Awards.

5 Projeto de Pesquisa intitulado "[RES_APO 1] Método de Análise da Resiliência e Adaptabilidade em Conjuntos Habitacionais Sociais Através da Avaliação Pós-Ocupação e Coprodução", relatório disponível em: https://morahabitacao.com/pesquisas-em-andamento-2/resapo/
} 
Quadro 1 - Instrumentos de APO aplicados.

\begin{tabular}{|c|c|c|c|c|c|}
\hline \multirow{2}{*}{ Instrumento } & \multirow{2}{*}{ Definição e Objetivos } & \multicolumn{2}{|c|}{ Ełapa 1 - Avaliando } & \multicolumn{2}{|c|}{ Ełapa 2 - Agindo } \\
\hline & & $\begin{array}{c}\text { Data de } \\
\text { Aplicação }\end{array}$ & Quantid. & $\begin{array}{c}\text { Data de } \\
\text { Aplicação }\end{array}$ & Quantid. \\
\hline $\begin{array}{l}\text { Coleta de } \\
\text { Dados }\end{array}$ & $\begin{array}{c}\text { Busca, por parte dos } \\
\text { pesquisadores, das principais } \\
\text { características do bairro } \\
\text { (dados ambientais, sociais, } \\
\text { econômicos, físico-urbanos e } \\
\text { físico-arquitetônicos) em } \\
\text { fontes confiáveis. }\end{array}$ & 2016 & - & 2018 & - \\
\hline $\begin{array}{l}\text { Questionário } \\
\text { do Morador }\end{array}$ & $\begin{array}{c}\text { Método quantitativo que } \\
\text { permite coleta de } \\
\text { informações relativas a } \\
\text { dados demográficos, renda, } \\
\text { escolaridade, comunicação, } \\
\text { saúde, violência, consumo } \\
\text { de água/energia, produção } \\
\text { de alimentos, lixo/poluição, } \\
\text { características construtivas } \\
\text { da habitação, qualidade } \\
\text { urbanística do entorno, entre } \\
\text { outros fatores, envolvendo a } \\
\text { percepção dos moradores } \\
\text { participantes. }\end{array}$ & $\begin{array}{c}05 / 07 / 2016 a \\
11 / 07 / 2016\end{array}$ & 40 & $\begin{array}{c}27 / 03 / 2018 \text { a } \\
20 / 04 / 2018\end{array}$ & 40 \\
\hline $\begin{array}{l}\text { Questionário } \\
\text { do } \\
\text { Pesquisador }\end{array}$ & $\begin{array}{l}\text { Método quantitativo que } \\
\text { permite a coleta de } \\
\text { informações relativas à } \\
\text { qualidade do entorno da } \\
\text { residência avaliada, estado } \\
\text { de conservação da } \\
\text { residência analisada, } \\
\text { orientação solar, acúmulo } \\
\text { de lixo, vegetação existente, } \\
\text { grau de modificação da } \\
\text { residência, comportamento } \\
\text { do morador, entre outros } \\
\text { fatores, envolvendo a } \\
\text { aferição e percepção dos } \\
\text { pesquisadores. }\end{array}$ & - & - & $\begin{array}{c}27 / 03 / 2018 \text { a } \\
20 / 04 / 2018\end{array}$ & 35 \\
\hline Walkthrough & $\begin{array}{c}\text { Método tanto qualitativo } \\
\text { como quantitativo para a } \\
\text { medição, análise e } \\
\text { identificação de aspectos } \\
\text { positivos e negativos do } \\
\text { ambiente construído, além } \\
\text { de sua situação atual, } \\
\text { avaliando os eixos temáticos: } \\
\text { i) lote e ii) unidade } \\
\text { habitacional. }\end{array}$ & $\begin{array}{c}08 / 07 / 2016 \text { a } \\
11 / 07 / 2016\end{array}$ & 04 & $\begin{array}{c}25 / 04 / 2018 a \\
16 / 05 / 2018\end{array}$ & 07 \\
\hline
\end{tabular}

Fonte: Autores, 2019.

A coprodução centrou-se em três elementos principais: (i) AMBIENTE CONSTRUÍDO - conjunto edificado contemplando as escalas do bairro, da vizinhança e da unidade, e as relações de impacto entre o ambiente construído e natural; (ii) AGENTES - agentes que interferem na dinâmica social do lugar e (iii) USUÁRIOS - moradores do conjunto. 
Vale ressaltar que o presente projeto de pesquisa, por lidar diretamente com a população, foi submetido a avaliação do Comitê de Ética em Pesquisa (CEP) da Universidade Federal de Uberlândia e aprovado sob o parecer de número 2.821 .800 .

\subsection{Estudo de caso: Conjunto Habitacional de Interesse Social do bairro Shopping Park - Loteamento Sucesso Brasil}

Localizado na região sul da cidade de Uberlândia, MG, o bairro Shopping Park estabeleceu-se lentamente desde a década de 1980, contudo, sofreu um crescimento exponencial a partir do ano de 2004. Atualmente é um bairro integrado composto por vários Loteamentos Residenciais, sendo que 8 desses loteamentos compõe o CHIS do bairro Shopping Park (figura 1). Esse CHIS começou a ser implantado em 2009, e em 2012 e 20133.632 unidades habitacionais foram entregues, todas destinados a faixa de renda 1 l0 a 3 salários mínimos), é um dos maiores CHIS já implantados na cidade de Uberlândia através do programa MCMV. O conjunto é composto em sua maioria por lotes residenciais de $200 \mathrm{~m}^{2}$, com casas de $36 \mathrm{~m}^{2}$ seguindo 0 padrão de casas geminadas (Figura 2).

O loteamento Sucesso Brasil é composto por 141 unidades habitacionais e foi escolhido como estudo de caso devido a dinâmica de seu entorno: proximidade com o principal centro de lazer do bairro, o Centro de Artes e Esportes Unificados (CEU), com o rio Uberabinha e com uma área de preservação permanente (APP). Como os demais loteamentos, o Sucesso Brasil apresenta desde sua implantação, sérios problemas construtivos, ambientais, econômicos e sociais, apontando a ineficiência do projeto, que deixa de fornecer moradia de qualidade, de acordo com o objetivo do programa MCMV.

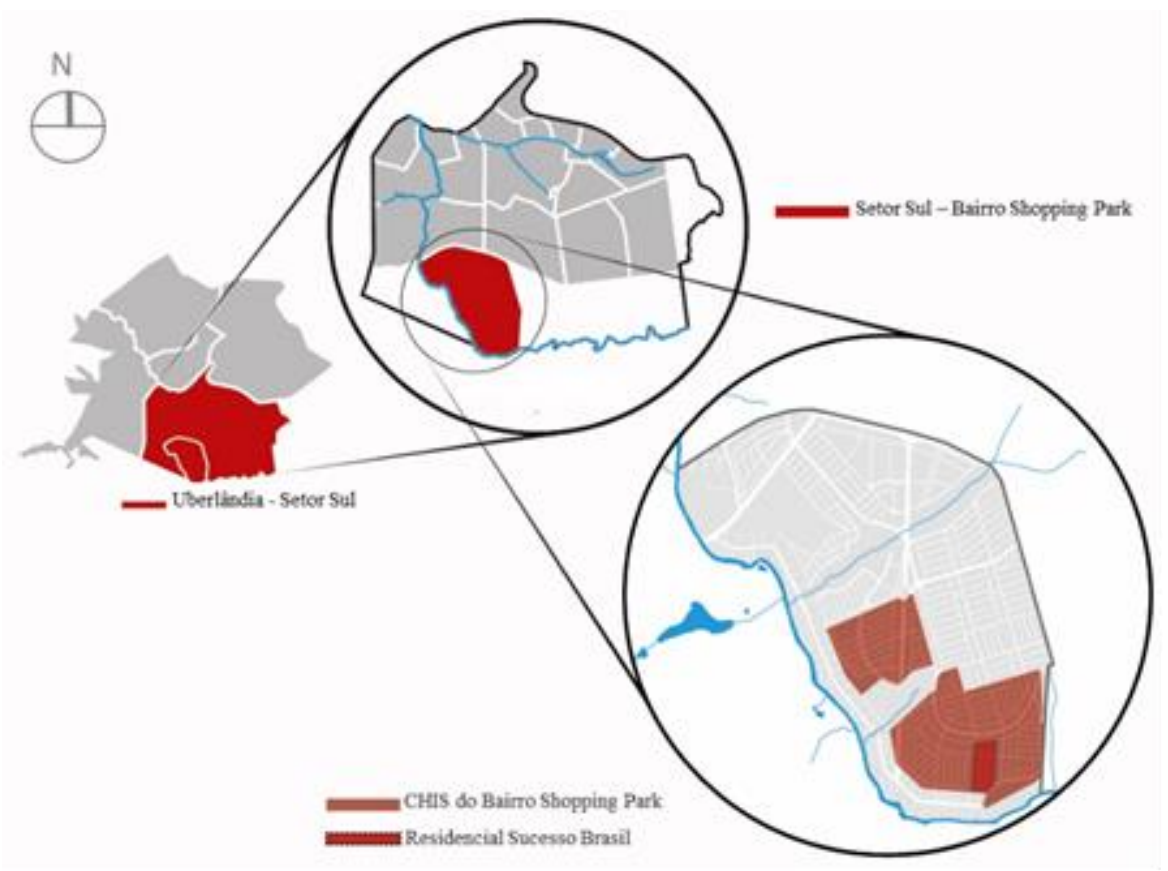

Figura 1 - CHIS Bairro Shopping Park.

Fonte: Villa et al. (2017), adaptado pelos autores (2019) 


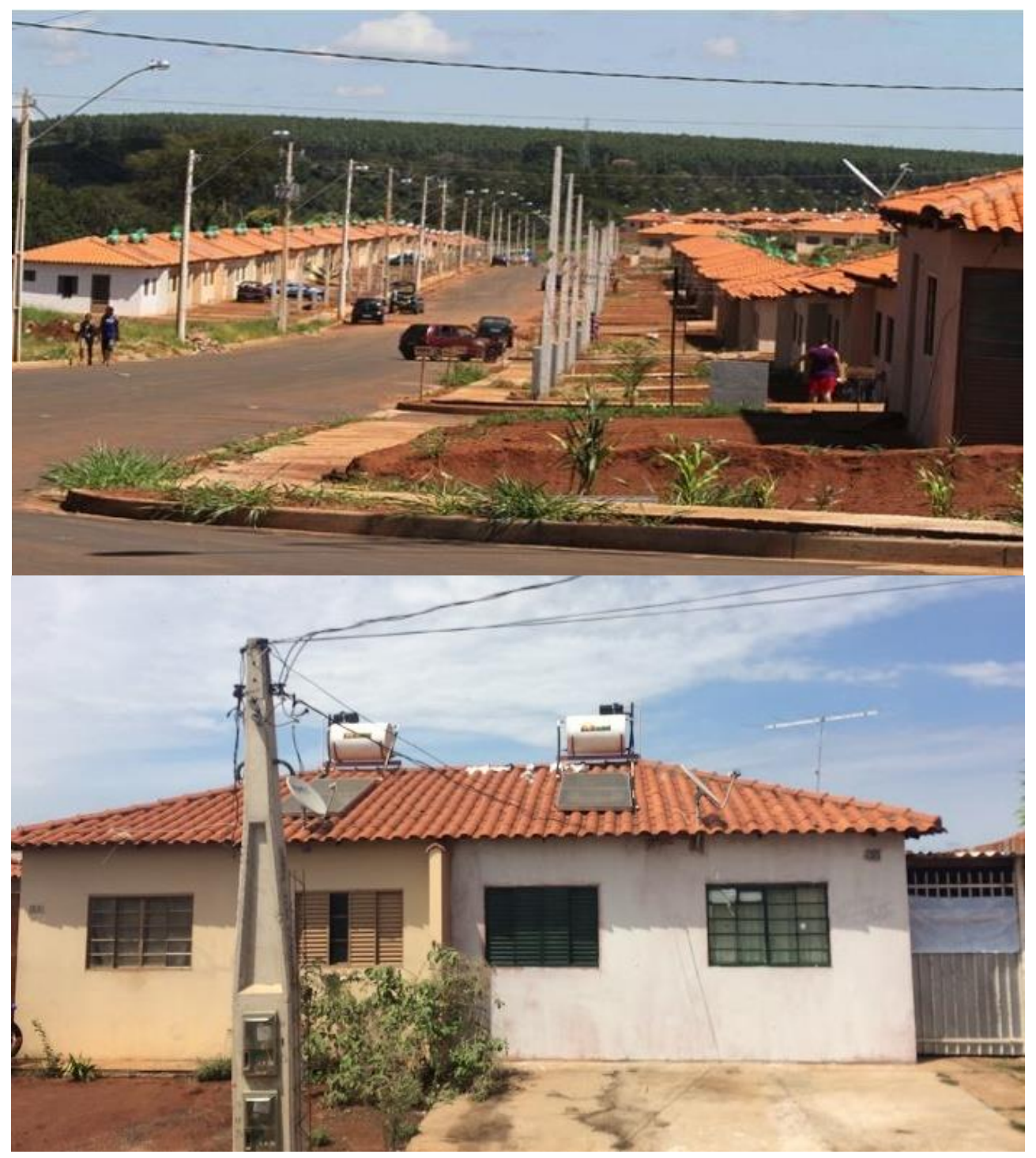

Figura 2 - Fotos rua do CHIS e casas geminadas.

Fonte: Villa et al. (2017)

\section{RESULTADOS E DISCUSSÃO}

Na etapa 1 (AVALIANDO) foram realizadas três coproduções que tiveram como principal objetivo identificar as principais vulnerabilidades e potencialidades da área de estudo de acordo com os moradores, bem como atuar como primeira aproximação entre o grupo de pesquisa e a comunidade local. Nas etapas 2 (AGINDO) e 3 (EMPODERANDO) foram realizadas três coproduções, duas atividades participativas e atualmente há uma coprodução em andamento (Figuras 3 e 4), no Quadro 2 cada coprodução é especificada, com objetivos e os resultados alcançados.

A partir da $5^{a}$ coprodução, o foco, que a princípio seria para uma escala urbana foi redirecionada para a escala da unidade habitacional. Isso ocorreu devido à falta de interesse da comunidade. A partir desta ótica os problemas apresentados pelos residentes e validados pelos resultados da APO foram: (i) baixa performance acústica, onde os níveis acústicos mínimos não atenderam 6 de 7 casas averiguadas; (ii) falta de áreas verdes em detrimento alta taxa de impermeabilização do solo, $40 \%$ das calçadas não possuem vegetação; (iii) 
dificuldade de armazenamento, $62,5 \%$ dos entrevistados estão insatisfeitos com o tamanho dos cômodos.; (iv) baixo desempenho térmico, as casas chegam a ter uma temperatura interna $4,3^{\circ} \mathrm{C}$ maior que a temperatura externa e (v) dificuldade na eliminação de resíduos, $35 \%$ das casas possuem excesso de resíduos desprotegidos.

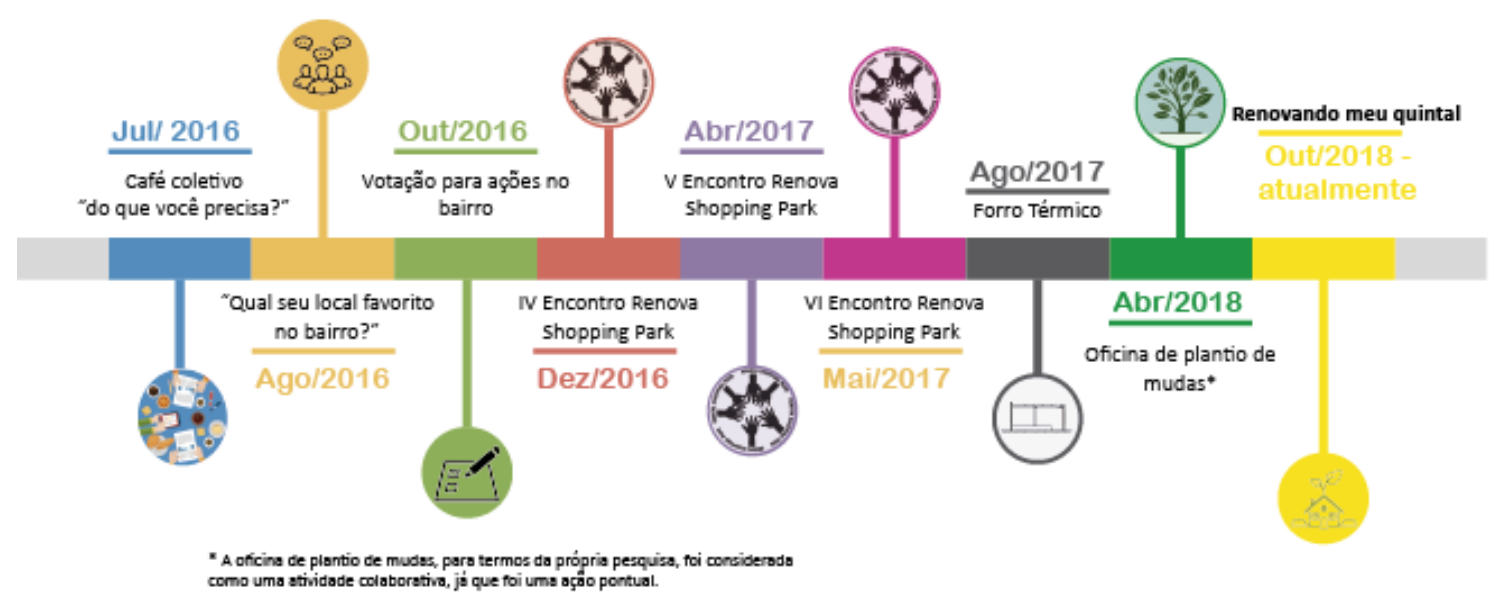

Figura 3 - Linha do tempo das coproduções.

Fonte: Autores (2019)

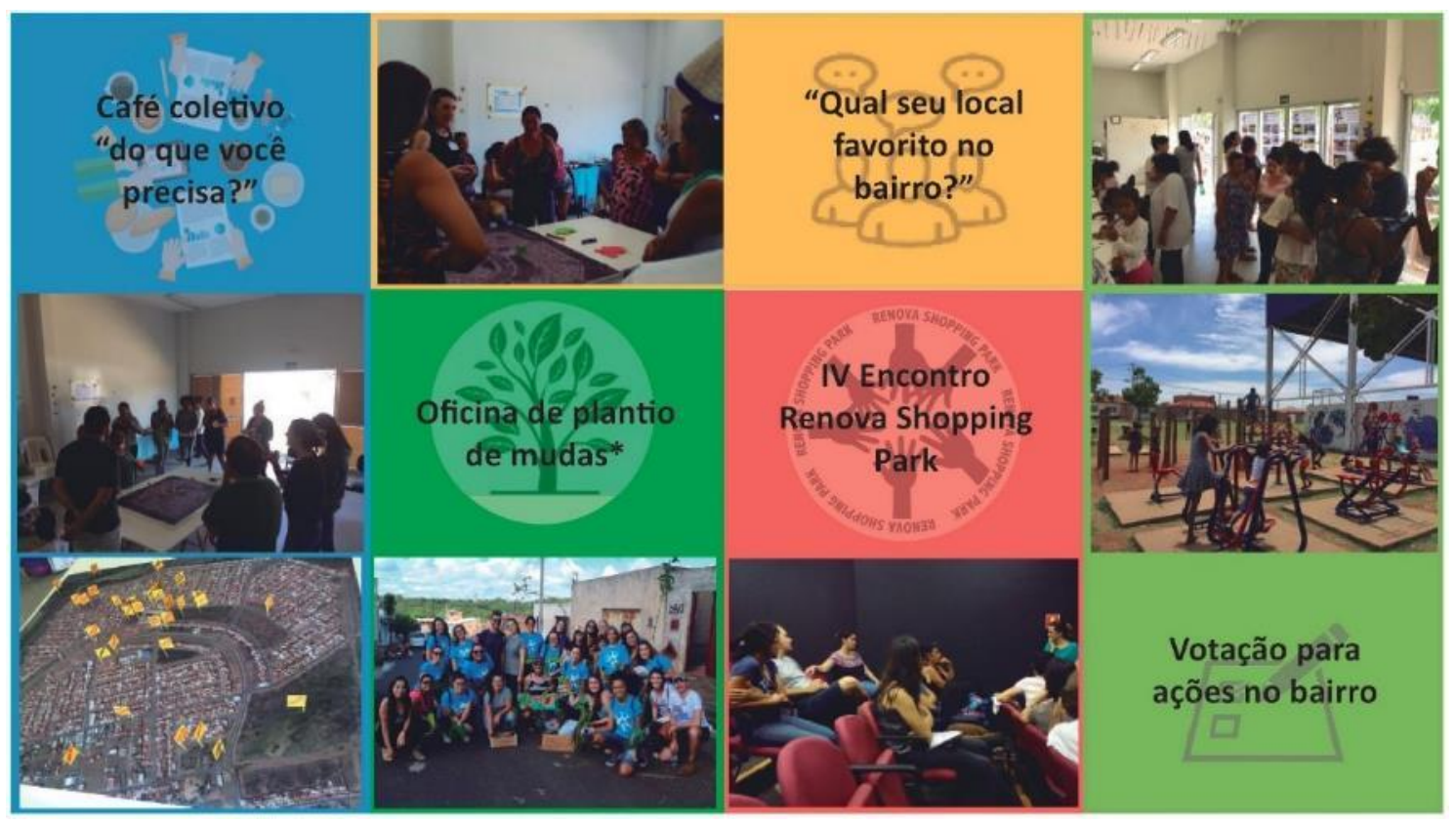

Figura 4 - Fotomontagem das coproduções.

Fonte: Autores (2019) 
Quadro 2 - Coproduções realizadas.

\begin{tabular}{|c|c|c|c|}
\hline $\begin{array}{c}\text { Número da } \\
\text { Coprodução - } \\
\text { Designação - } \\
\text { Data }\end{array}$ & Objetivos & Resultados & $\begin{array}{l}\text { Número } \\
\text { estimado de } \\
\text { participantes }\end{array}$ \\
\hline $\begin{array}{l}1 \text { - Café } \\
\text { Coletivo "do } \\
\text { que você } \\
\text { precisa?" - } \\
09 / 07 / 2016\end{array}$ & $\begin{array}{l}\text { Apresentar a pesquisa, } \\
\text { seus objetivos e } \\
\text { metodologias, para a } \\
\text { comunidade do bairro } \\
\text { Shopping Park. Além } \\
\text { disso ouvir e discutir com } \\
\text { os moradores sobre as } \\
\text { problemáticas que eles } \\
\text { veem sobre o seu bairro. }\end{array}$ & $\begin{array}{l}\text { A coprodução centrou-se em ouvir } \\
\text { a população, para isso em um } \\
\text { mapa os moradores elencaram os } \\
\text { elementos do bairro e levaram em } \\
\text { discussão suas sugestões diante } \\
\text { das problemáticas do bairro. As } \\
\text { crianças também tiveram voz } \\
\text { gerando desenhos com suas } \\
\text { percepções do bairro. Neste foi } \\
\text { escolhido o nome do projeto no } \\
\text { bairro, Renova Shopping Park, e } \\
\text { também foi estabelecido um } \\
\text { canal de comunicação com a } \\
\text { comunidade. }\end{array}$ & $\begin{array}{l}7 \text { adultos e } 6 \\
\text { crianças }\end{array}$ \\
\hline $\begin{array}{c}2 \text { - "Qual o seu } \\
\text { local favorito no } \\
\text { bairro?" - } \\
\text { 07/08/2016 }\end{array}$ & $\begin{array}{l}\text { Desenvolver as discussões } \\
\text { iniciadas anteriormente, } \\
\text { além de entender as } \\
\text { potencialidades do } \\
\text { bairro, e, portanto, dar } \\
\text { voz à comunidade. }\end{array}$ & $\begin{array}{c}\text { Foram identificadas, após o } \\
\text { evento, cinco possíveis ações pela } \\
\text { professora Fionn Stevenson da } \\
\text { Universidade de Sheffield: } \\
\text { resolução do desconforto dentro } \\
\text { das UHs (acústico e térmico) com } \\
\text { materiais baratos e alternativos, a } \\
\text { instalação de muros verdes nas } \\
\text { residências, a criação de um eco } \\
\text { parque no bairo como um } \\
\text { ambiente de convívio, a criação } \\
\text { de um eco ponto para reciclagem } \\
\text { (já que a grande quantidade de } \\
\text { lixo jogado nas ruas e nos lotes } \\
\text { vagos é um grave problema do } \\
\text { bairro) e a instalação de abrigos } \\
\text { em pontos de ônibus. }\end{array}$ & 27 adultos \\
\hline $\begin{array}{c}3 \text { - "Votação } \\
\text { para ações no } \\
\text { bairro" - } \\
\text { 12/10/2016 }\end{array}$ & $\begin{array}{l}\text { Com as propostas } \\
\text { levantadas, foi realizada } \\
\text { uma votação com os } \\
\text { moradores do bairro. As } \\
\text { ações foram mais } \\
\text { centradas em } \\
\text { qualificações } \\
\text { urbanísticas, ou seja, para } \\
\text { o bairro como um todo e } \\
\text { não especificamente } \\
\text { para as UHs. }\end{array}$ & $\begin{array}{l}\text { A ação mais votada foi a } \\
\text { instalação de um eco parque no } \\
\text { bairro. A terceira Coprodução foi } \\
\text { importante para reforçar o grupo } \\
\text { Renova Shopping Park dentro do } \\
\text { bairro. }\end{array}$ & $\begin{array}{l}41 \text { adultos e } 25 \\
\text { crianças }\end{array}$ \\
\hline $\begin{array}{l}4 \text { - IV Encontro } \\
\text { Renova } \\
\text { Shopping Park - } \\
11 / 12 / 2016\end{array}$ & $\begin{array}{l}\text { Apresentar o resultado da } \\
\text { votação da Coprodução } \\
\text { 3, que tinha como foco } \\
\text { realizar uma intervenção } \\
\text { na escala urbana, onde } \\
\text { foi escolhida a } \\
\text { implantação de um } \\
\text { parque ecológico e a } \\
\text { limpeza desse parque. }\end{array}$ & $\begin{array}{l}\text { Falta de interesse da comunidade, } \\
\text { mudança do foco da pesquisa, } \\
\text { para desenvolver algumas ações } \\
\text { que poderiam ocorrer dentro das } \\
\text { unidades habitacionais. }\end{array}$ & $\begin{array}{l}1 \text { adulto e } 6 \\
\text { crianças }\end{array}$ \\
\hline
\end{tabular}




\begin{tabular}{|c|c|c|c|}
\hline $\begin{array}{l}5 \text { - V Encontro } \\
\text { Renova } \\
\text { Shopping Park - } \\
04 / 04 / 2017\end{array}$ & $\begin{array}{c}\text { Listar os principais } \\
\text { problemas das unidades } \\
\text { habitacionais e discutir } \\
\text { meios para resolvê-los ou } \\
\text { mitigá-los. }\end{array}$ & $\begin{array}{c}\text { Cinco grandes problemas foram } \\
\text { identificados. Os participantes } \\
\text { ofereceram suas casas para as } \\
\text { próximas reuniões. }\end{array}$ & 3 adultos \\
\hline $\begin{array}{l}\text { 6- VI Encontro } \\
\text { Renova } \\
\text { Shopping Park - } \\
11 / 05 / 2017\end{array}$ & $\begin{array}{c}\text { Apresentação dos } \\
\text { principais problemas } \\
\text { encontrados nas } \\
\text { unidades habitacionais e } \\
\text { os meios para resolvê-los } \\
\text { ou mitigá-los. }\end{array}$ & $\begin{array}{l}\text { Interesse dos participantes em } \\
\text { resolver os principais problemas } \\
\text { encontrados. Predefinição de } \\
\text { algumas ações dentro das } \\
\text { unidades habitacionais. }\end{array}$ & $\begin{array}{c}8 \text { adultos e } 4 \\
\text { crianças }\end{array}$ \\
\hline $\begin{array}{l}7 \text { - Coprodução } \\
\text { Forro Térmico - } \\
25 / 08 / 2017\end{array}$ & $\begin{array}{l}\text { Elaboração do forro tetra } \\
\text { park com o intuito de } \\
\text { solucionar o problema } \\
\text { térmico das casas, mas } \\
\text { com custo reduzido. }\end{array}$ & $\begin{array}{l}\text { Inicialmente, essa atividade foi } \\
\text { proposta para ser o primeiro } \\
\text { problema a ser resolvido, mas } \\
\text { foram encontrados alguns } \\
\text { obstáculos e ela não foi concluída } \\
\text { efetivamente. Contudo a } \\
\text { coprodução se tornou objeto de } \\
\text { discussão e questionamento para } \\
\text { serem atentados nas próximas } \\
\text { coproduções. }\end{array}$ & 1 adulto \\
\hline $\begin{array}{l}\text { Atividade } \\
\text { Participativa - } \\
\text { Oficina de } \\
\text { Plantio de } \\
\text { Mudas - } \\
\text { 07/04/2018 }\end{array}$ & $\begin{array}{l}\text { Plantio de mudas nas } \\
\text { calçadas e quintais. } \\
\text { Aproximação da } \\
\text { população da área. }\end{array}$ & $\begin{array}{l}\text { Plantio de mudas frutíferas e } \\
\text { ornamentais em } 15 \text { casas. } \\
\text { Estreitamento da relação entre } \\
\text { pesquisadores e moradores. } \\
\text { Levantamento de moradores que } \\
\text { tinham interesse em futuras } \\
\text { coproduções. }\end{array}$ & $\begin{array}{c}15 \text { casas } \\
\text { participantes }\end{array}$ \\
\hline $\begin{array}{l}8 \text { - "Renovando } \\
\text { meu quintal" - } \\
22 / 10 / 2018\end{array}$ & $\begin{array}{c}\text { Coprodução } \\
\text { denominada como } \\
\text { "Renovando Meu } \\
\text { Quintal", busca promover } \\
\text { melhorias na área externa } \\
\text { das residências. }\end{array}$ & $\begin{array}{l}\text { Coprodução em andamento. } \\
\text { Desenvolvimento de projetos para } \\
\text { a área externa da casa de duas } \\
\text { moradoras, resolvendo } \\
\text { problemáticas pontuais e } \\
\text { pretendendo desenvolver a } \\
\text { resiliência em nível local. }\end{array}$ & $\begin{array}{c}5 \text { adultos e } 3 \\
\text { crianças }\end{array}$ \\
\hline
\end{tabular}

Fonte: Autores, 2019.

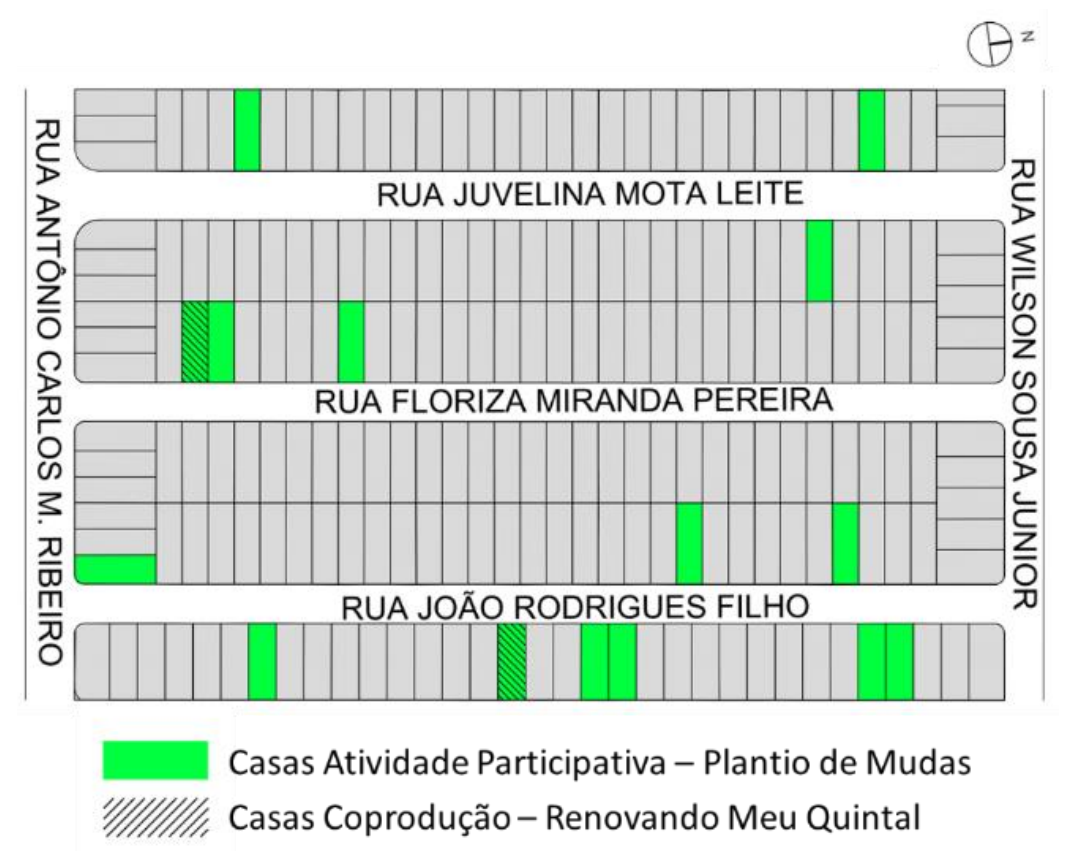

Figura 5 - Localização das casas da Atividade Participativa e da $8^{a}$ Coprodução.

Fonte: Autores (2019) 
Assim, com as problemáticas elencadas, as coproduções posteriores foram destinadas a minimização desses fatores. Por conseguinte, a "7 Coprodução Forro térmico" foi realizada com o intuito de prover um melhor desempenho térmico no interior das casas e deste modo reverter o cenário apresentado pela problemática (iv).

Para esse artigo, serão melhor detalhados a atividade colaborativa de plantio de mudas e a coprodução em andamento, denominada "Renovando meu quintal", ações que possuem a finalidade de aumentar o índice de áreas verdes no bairro. A realização da $8^{\circ}$ coprodução, ocorreu como consequência da atividade colaborativa de plantio de mudas como pode ser observado na figura 5.

\subsection{Atividade Colaborativa Plantio de Mudas}

As problemáticas elencadas nas coproduções anteriores foram fundamentais para dar respaldo a Atividade Colaborativa de Plantio de Mudas, principalmente sobre a falta de áreas verdes nas habitações e no meio urbano. Ademais, de acordo com os resultados obtidos na aplicação da APO, $87,5 \%$ dos residentes possuem algum tipo de planta em casa, $60 \%$ ainda sente falta de áreas verdes, $47,5 \%$ produz algum tipo de horta em casa. Portanto, apesar do contato da maior parte dos moradores com algum tipo de vegetação, as áreas verdes no bairro e dentro de suas casas são insuficientes, principalmente devido à alta taxa de impermeabilização do solo em ambas estâncias.

Esta ação (Figura 6) foi fruto da união da pesquisa RES_APO com o grupo de pesquisa Rede Azulb, aliança essa que potencializou a metodologia coprodutiva de trabalho, beneficiando novas possibilidades de interação e de trocas de conhecimento em detrimento da solução das problemáticas da região. A ação foi desempenhada com alguns objetivos em mente, como a procura por mais moradores dispostos a participar do projeto e atender 0 problema relatado pela coprodução anterior sobre a falta de áreas verdes nas habitações.

Uma variedade de mudas foram plantadas, desde plantas com propriedades medicinais, plantas frutíferas e plantas ornamentais no qual durante a atividade os membros das pesquisas tinham o cuidado de explicar aos moradores seus benefícios e dicas de cultivo.

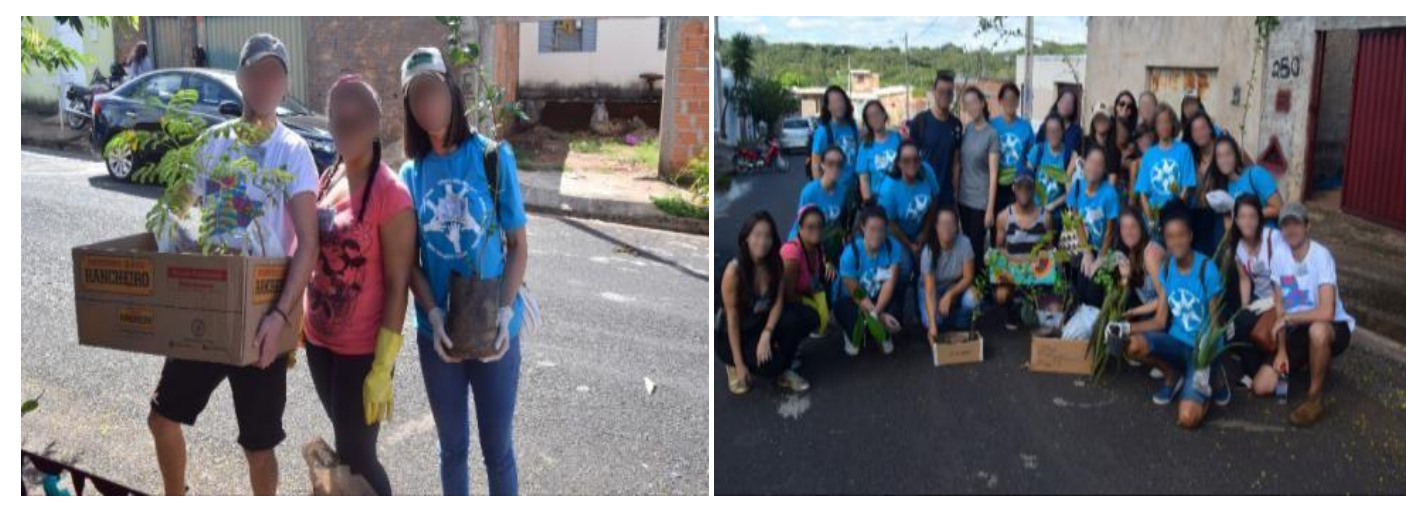

Figura 6 - Atividade Colaborativa.

Fonte: Autores (2018) 6 Rede Azul - Projeto desenvolvido pelo Núcleo de Estudos Urbanos (NEURB) da Faculdade de
Arquitetura e Urbanismo e Design (FAUeD). 
A ação obteve sucesso na aplicação da metodologia e contribuiu na aproximação do grupo de pesquisa com a comunidade, aumentando o interesse dos moradores junto a pesquisa e colaborando para a abertura de interessados e engajados para futuras coproduções. Outro fator positivo foi a valorização do engajamento na comunidade, trazendo uma melhor relação entre os vizinhos e configurando maior apropriação física dos espaços urbanos.

\subsection{Coprodução - Renovando o meu quintal}

Atualmente a coprodução "Renovando o meu quintal" está em curso com foco em melhorar a área externa de algumas residências do bairro, retomando as discussões sobre a falta de áreas verdes nas residências e buscando empoderar a comunidade através da resiliência em nível local.

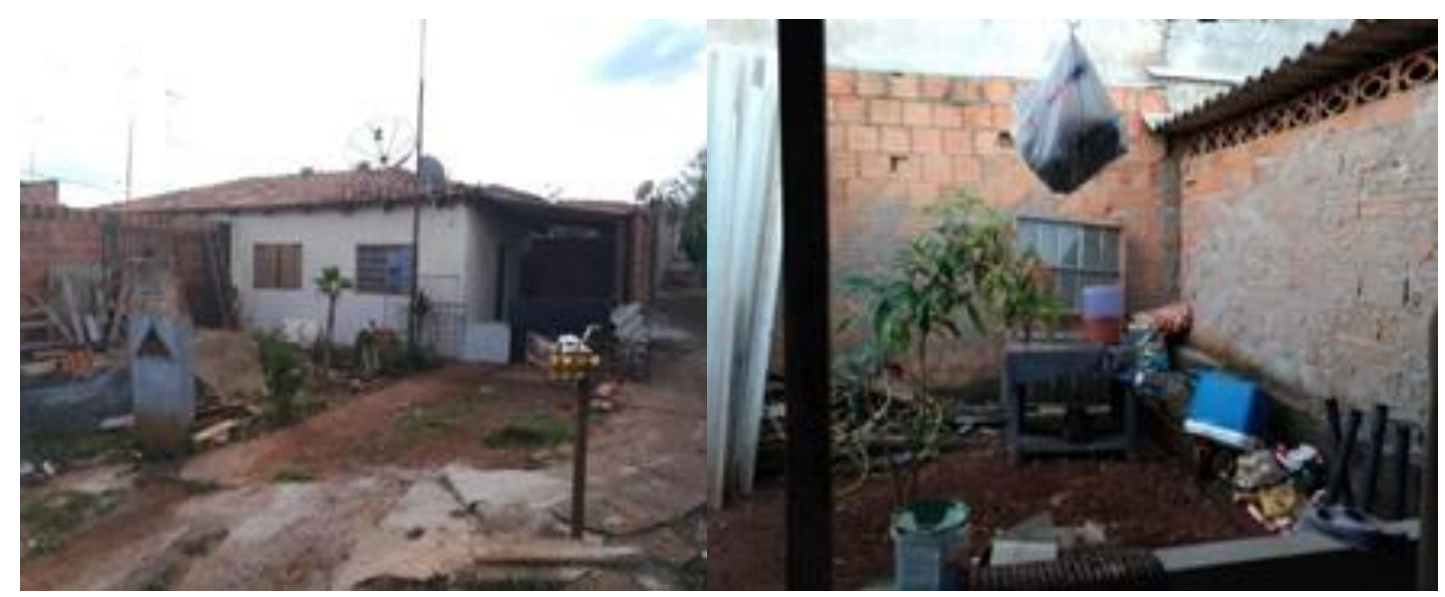

Figura 7 - Acúmulo de entulho nos lotes.

Fonte: Autores (2018)

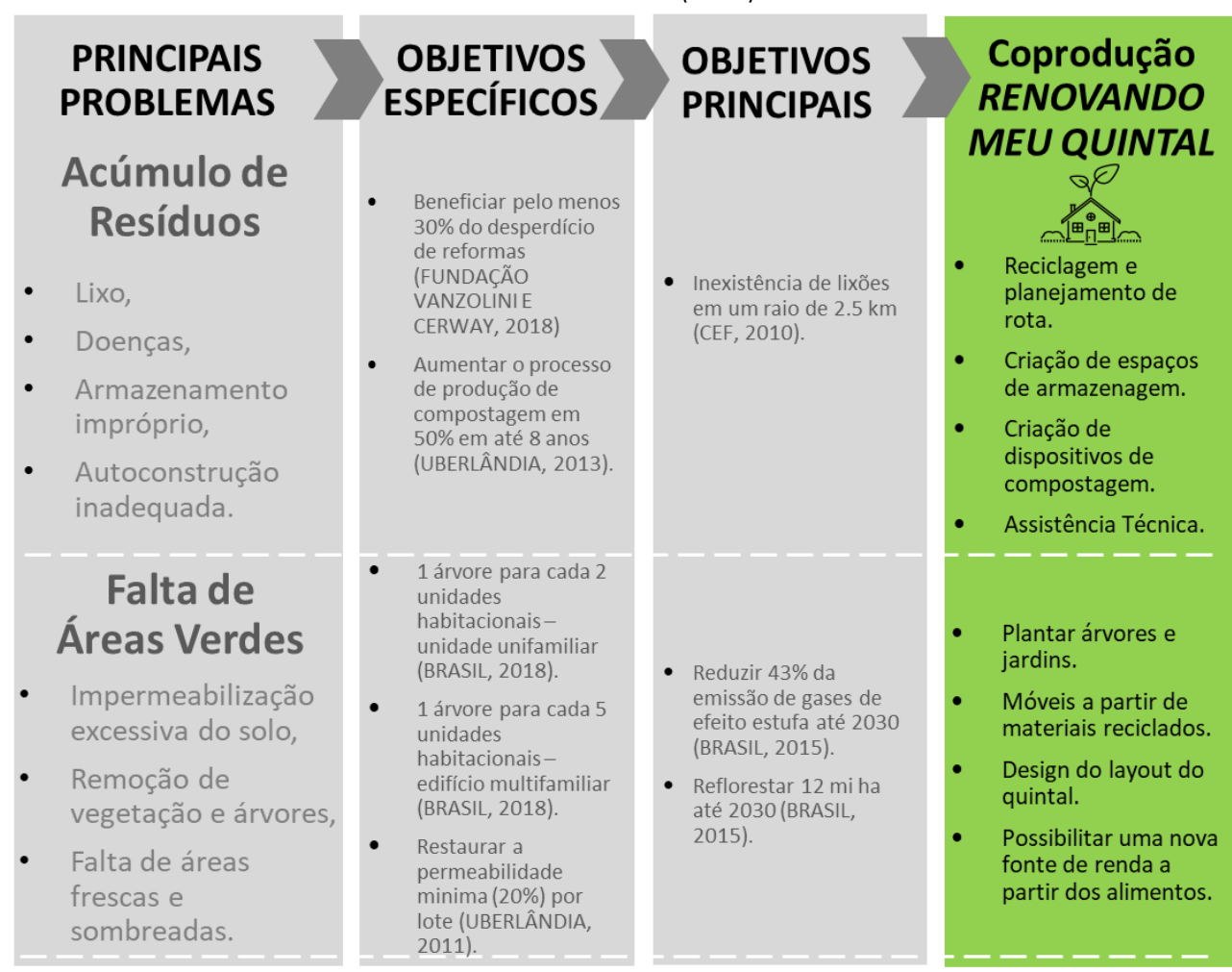

Figura 8 - Problemas e objetivos que levaram à $8^{a}$ coprodução.

Fonte: Autores (2019) 
Tendo como ponto de partida as problemáticas já listadas neste artigo, a coprodução propõe minimizar dois problemas principais, o acúmulo de resíduos (Figura 7) e a falta de áreas verdes, e consequentemente atender objetivos específicos e objetivos principais que orientaram as tomadas de decisões e, portanto, as ações a serem realizadas nas casas (Figura 8). Desse modo a coprodução além de instigar a resiliência local também cumpre com as agendas nacionais e internacionais de desenvolvimento sustentável.

A atividade colaborativa "plantio de mudas" foi fundamental para elencar as duas casas participantes da coprodução,o projeto de intervenção nos quintais foi desenvolvido por meio de um processo coparticipativo, de muita discussão, reuniões, levantamentos e observações (Figura 9).

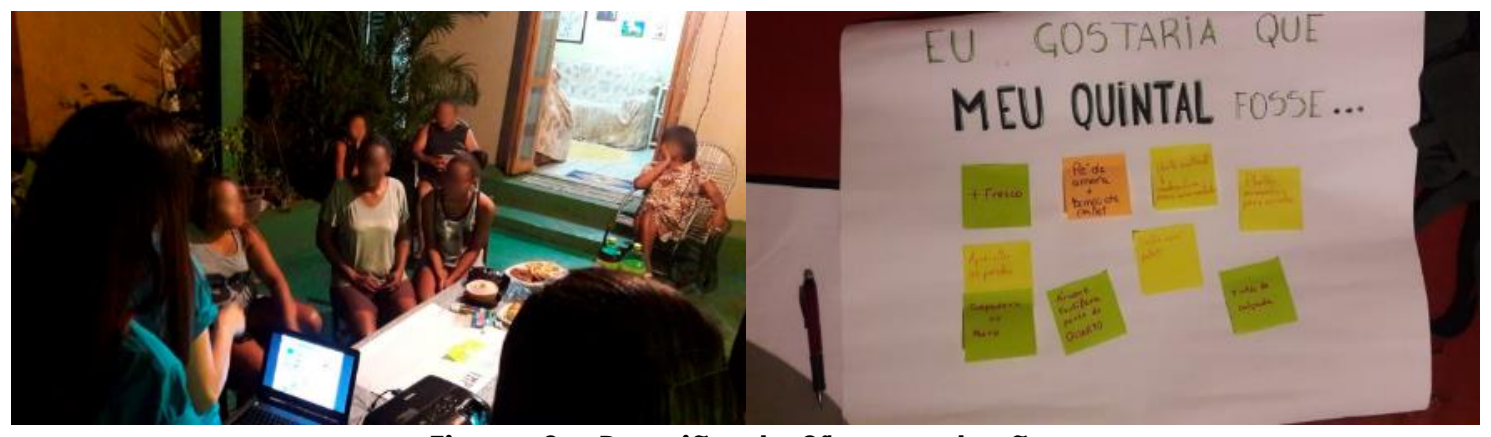

Figura 9 - Reunião da $8^{a}$ coprodução.

Fonte: Autores (2018)

Os projetos incentivam a reutilização de materiais, a produção de móveis exequíveis e impulsiona o plantio de plantas com a intenção de mudar o baixo índice de áreas permeáveis e áreas verdes. Ademais, tais ações são pontuais e tem como priori serem executáveis em outras situações em outras casas da vizinhança, tonando-se bons exemplos e boas soluções para as áreas externas (Figuras 10).

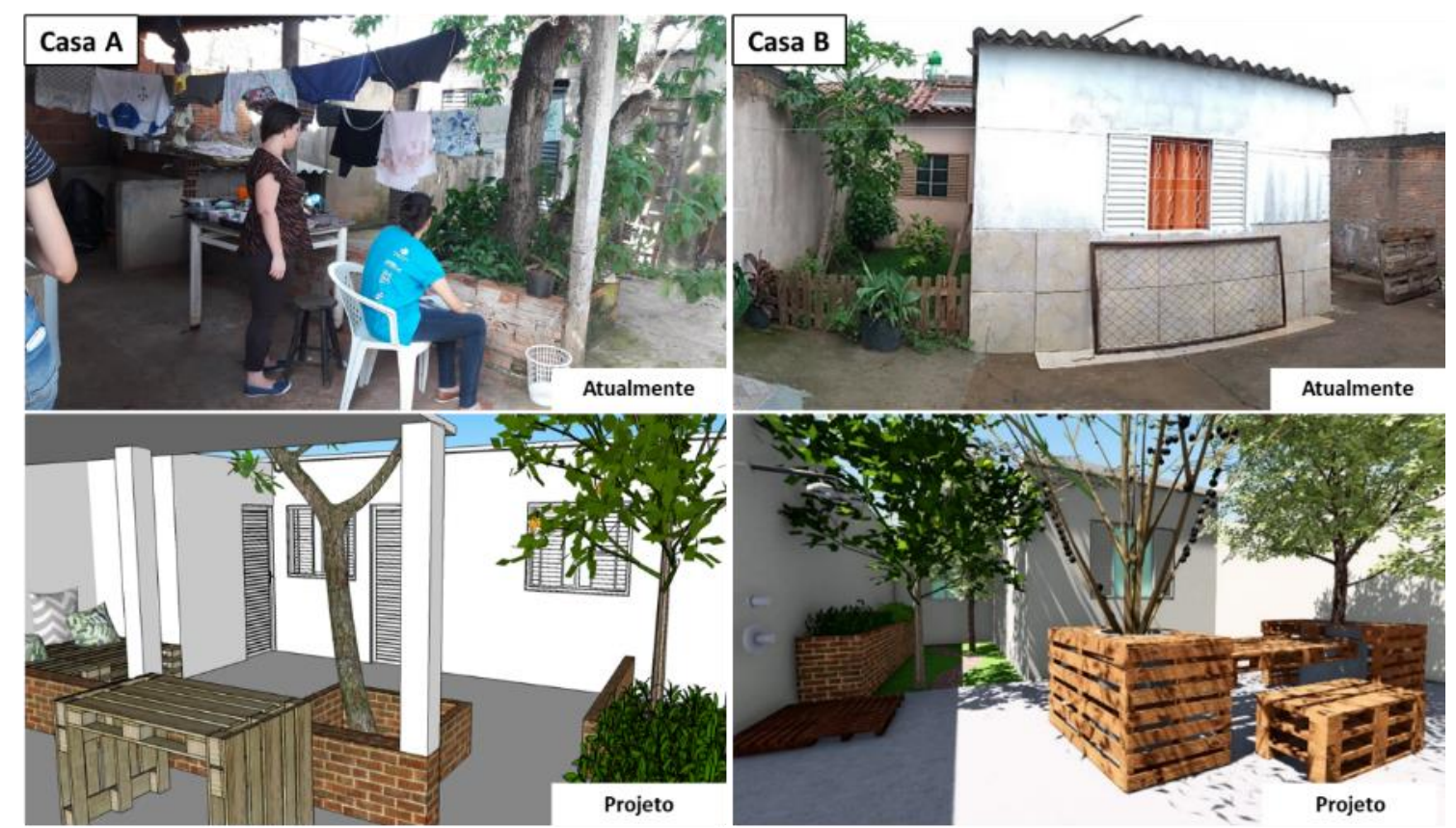

Figura 10 - Área externa das casas, atualmente e projeto.

Fonte: Autores (2019) 
O projeto foi detalhado e os materiais necessários orçados, assim a fase atual busca patrocinadores através do site de financiamento coletivo "Catarse" (Figura 11), para que assim se faça possível executar o projeto de ambas as áreas externas.

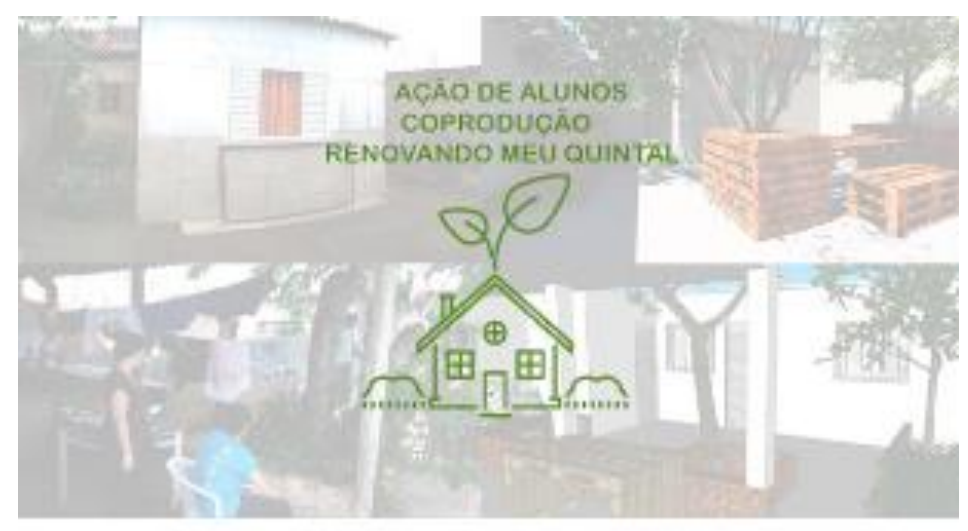

\section{Ação de alunos - Projeto Renova Shopping Park}

por Renova Shopping Park

Apoie essa ação de alunos para renovar o
quintal e a vida de duas moradoras do
bairro Shopping Park.

Figura 11 - Card de apresentação do financiamento coletivo.

Fonte: Autores (2019)

\section{CONSIDERAÇÕES FINAIS}

Através dessa experiência do uso da metodologia de coprodução como ferramenta de promoção e melhoria da resiliência em comunidades de CHIS, é possível comprovar sua relevância. Observa-se nessas comunidades uma grande capacidade adaptativa dos moradores frente à inúmeras adversidades, sejam construtivas, socioeconômicas ou ambientais, pois estão sempre buscando formas de melhorar seu ambiente construído, porém na maioria das vezes essas adaptações são muito restritas e paliativas, não sendo completamente eficazes. Nesse contexto a coprodução se mostra uma excelente ferramenta de prática colaborativa para promoção da resiliência, otimizando as melhorias das residências feitas pelos moradores, através de troca de conhecimento e orientação técnica por parte dos pesquisadores, que buscam desenvolver, em conjunto com a comunidade, soluções passíveis de serem replicadas e sustentáveis, o que alinha esta pesquisa a agendas nacionais e internacionais de desenvolvimento sustentável.

Essa pesquisa visa promover mudanças reais e práticas aos residentes do conjunto habitacional de interesse social em estudo, elevando seus índices de resiliência e de capacidade adaptativa, para isso os instrumentos de avaliação utilizados foram desenvolvidos especificamente para esta pesquisa e vêm sendo aprimorados e reaplicados ao longo do tempo a fim de chegar 
a parâmetros e indicadores de resiliência e empoderamento cada vez mais objetivos. Objetiva-se também fornecer informações e aspectos a serem melhorados nos futuros projetos de CHIS que forem ofertados pelo poder público, a fim de promover ampliação da capacidade adaptativa e da resiliência do ambiente construído desses conjuntos, e, portanto, da qualidade de vida de seus moradores.

\section{AGRADECIMENTOS}

Ao CNPq, à FAPEMIG e à UFU, pelo apoio recebido.

\section{REFERÊNCIAS}

ADGER, W. N. Social and ecological resilience: are they related? Progress in Human Geography, 24: 347-64. 2000.

AMORE, C. S.; SHIMBO, L. Z.; RUFINO, M. B. (ORG) MINHA Casa...E a Cidade? Avaliação do programa minha casa minha vida em seis estados brasileiros. Rio de Janeiro: Letra Capital, 2015.

$\mathrm{BOHM}, \mathrm{T}$. Minha Casa Minha Vida não reduziu déficit habitacional, afirma estudo. Jornal do Senado, Brasília, 20 fev. 2018. Disponível em: < https://www2.senado.leg.br/bdsf/bitstream/handle/id/538499/Cidadania_622. pdf? sequence $=1$ > Acesso em: 16 fev. 2019.

BRASIL. Portaria $n^{\circ}$ 660, de 14 de novembro de 2018. Diretrizes para a elaboração de projetos e estabelece as especificações técnicas mínimas da unidade habitacional e as especificações urbanísticas dos empreendimentos destinados à aquisição e alienação com recursos advindos da integralização de cotas no Fundo de Arrendamento Residencial - FAR, e contratação de operações com recursos transferidos ao Fundo de Desenvolvimento Social FDS, no âmbito do Programa Minha Casa, Minha Vida - PMCMV.

BRASIL. Pretendida Contribuição Nacionalmente Determinada Para Consecução Do Objetivo Da Convenção-Quadro Das Nações Unidas Sobre Mudança Do Clima. Brasília, DF, 2015.

CAIXA ECONÔMICA FEDERAL (CEF). Selo Casa Azul - Boas Práticas para Habitação mais Sustentável. Brasília, DF, 2010.

ELALI, G. A.; VELOSO, M. Estudos de Avaliação Pós-Ocupação na Pósgraduação: uma perspectiva para a incorporação de novas vertentes. Seminário Internacional NUTAU, 2004, Anais, São Paulo: NUTAU, 2004.

FUNDAÇÃO VANZOLINI E CERWAY. Edifícios Residenciais Em Construção AQUA-HQE ${ }^{T M}$ Certificado pela Fundação Vanzolini e Cerway- Referencial de Avaliação da Qualidade Ambiental de Edifícios Residenciais em Construção. São Paulo, SP, 2018.

GRANJA, A. D.; KOWALTOWSKI, D. C. C. K.; PINA, S. A. M. G.; FONTANINI, P. S. P.; BARROS, L. A. F.; PAOLI, D.; JACOMIT, A. M.; MAÇANS, R. M. A. A natureza do valor desejado na habitação social. Ambiente Construído, Porto Alegre, v.9, n.2, p. 87-103, abr./jun. 2009.

INTERGOVERNMENTAL PANEL ON CLIMATE CHANGE (IPCC). Climate change 2014: impacts, adaptation and vulnerability. Contribution of Working Group II to 
the Fifth Assessment Report of the Intergovernmental Panel on Climate Change. Cambridge: Cambridge University Press, 2014.

KELLY, G. Communities coping with change: a conceptual model. Journal of Community Psychology, 32: 201-16. 2004.

LEAMAN, A.; STEVENSON. F.; BORDASS, B. Building Evaluation: Practice and Principles. Building Research and Information 38 (5): 564-577, 2010.

MAGUIRE, B. \& CARTWRIGHT, S. Assessing a community's capacity to manage change: A resilience approach to social assessment. Canberra: Australian Government Bureau of Rural Sciences, 2008.

MALLORY-HILL, S.; PREISER, W. F.E.; WATSON, C. (edits). Enhancing Building Performance. Oxford, UK: Wiley-Blackwell, 2012. 330p.

MEEROW, S., NEWELL, J. P. \& STULTS, M. Defining urban resilience: A review. In Landscape and Urban Planning. Michigan, v. 147, p. 38-49, dez. 2015.

Disponível em: <https://doi.org/10.1016/j.landurbplan.2015.11.011>. Acesso em: 16 fev. 2019.

ONO, R.; ORNSTEIN, S. W.; VILLA, S. B.; FRANÇA, A. J. G. L. (Org.) Avaliação PósOcupação (APO) na Arquitetura, no Urbanismo e no Design: da Teoria à Prática. São Paulo: Oficina de Textos, 2018.

ORNSTEIN, S. W.; VILLA, S. B.; ONO, R. Residential high-rise buildings in São Paulo: aspects related to the adequacy to the occupant s needs. Journal of Housing and the Built Environment, v. 26, 2011, p. 73-84.

PETCOU, C. \& PETRESCU, D. R-URBAN or how to produce a resilient city. In EPHEMERA Theory \& Polytics Organization. Sheffield, v. 15 (1), p. 249-262, 2015. Disponível em: < http://www.ephemerajournal.org/contribution/r-urban-orhow-co-produce-resilient-city>. Acesso em 14 fev. 2019.

PREISER, W. F.E.; VISCHER, J. C. (edits). Assessing Building Performance. Oxford, UK: Elsevier, 2005. 243p.

STEVENSON, F. \& PETRESCU, D. Co-producing neighbourhood resilience. In Building Research \& Information. Sheffield, v. 44, n.7, p. 695-702, Ago. 2016. Disponível em: <https://doi.org/10.1080/09613218.2016.1213865>. Acesso em 14 fev. 2019.

THACKARA, J. City Eco Lab: thing-design to-do list. In Conference Doors of Perception, December 05, 2008. Disponível em: <

http://www.doorsofperception.com/archives/2008/12/design_opportun.php>. Acesso em 03 jun. 2019.

UBERLÂNDIA. Lei Complementar $n^{\circ}$ 525, de 14 de abril de 2011. Zoneamento do Uso e Ocupação do Solo do Município de Uberlândia.

UBERLÂNDIA. Plano de Gestão Integrada de Resíduos Sólidos do Município de Uberlândia. Uberlândia, MG, 2013.

VILLA, S. B.; ORNSTEIN, S. W. (Org.) Qualidade ambiental na habitação: avaliação pós-ocupação. São Paulo: Oficina de Textos, 2013. p.359-378.

VOORDT, T. J.M. van der; WEGEN, H. B.R. Arquitetura sob o olhar do usuário. Programa de necessidades, projeto e avaliação de edificações. São Paulo: Editora Oficina de Textos, 2013. 237p. 
WALKER, B.; HOLLING, C.; CARPENTER, S. e KINZIG, A. Resilience, adaptability and transformability in social: ecological systems. Ecology and Society, 9 (2), 5, 2004. 